\title{
Informação, Comunicação e Saúde: campo interdisciplinar em construção
}

\author{
Carolina Pires Araújo ${ }^{1}$ \\ (carolpa_com@yahoo.com.br)
}

\begin{abstract}
Resumo
O cenário atual vem se configurando a partir de novos modelos e paradigmas. Uma questão em voga é a interdisciplinaridade, a qual tem se colocado como uma possibilidade eficaz para resolver problemáticas contemporâneas. É justamente nesse contexto que se estabelece a configuração de um novo campo, o da 'Informação, Comunicação e Saúde'. O presente estudo propõe, assim, investigar o desenvolvimento desse campo, a partir de uma revisão de literatura. Para tanto, o trabalho se divide em três partes. Na primeira, será realizada uma pesquisa sobre o contexto da Saúde em busca de entender sua trajetória histórica, epistemológica, social e científica. Num segundo momento, será traçada a trajetória dos campos da Saúde e das Ciências Sociais, expondo a condição interdisciplinar que entre elas se instaura. A terceira parte, por sua vez, tem como propósito apontar as diretrizes do campo em formação, as quais se inserem no contexto das mediações. Nesse sentido, as disputas e tensões constituem a formação do campo, o qual deve ser socialmente construído.
\end{abstract}

Palavras-chave: Interdisciplinaridade. Informação. Comunicação. Saúde.

\section{Information, Communication and Health: interdisciplinary field development}

\begin{abstract}
The current scenario has emerged from new models and paradigms. One issue in vogue is interdisciplinary, which has been placed as an effective possibility to solve contemporary problems. It is precisely in this context that establishes the configuration of a new field, the 'Information, Communication and Health. The present study proposes to investigate the development of this field, from a literature review. For this, the work is divided into three parts. At first, there will be a survey of the context of Health seeking to understand its historical trajectory, epistemological, social and scientific. Secondly, the trajectory will be drawn from the fields of Health and Social Sciences, exposing the interdisciplinary condition established between them. The third part aims to point out the guidelines of field training, which fall within the context of mediation. In that way, the disputes and tensions are the training field, which must be socially constructed.
\end{abstract}

Keywords: Interdisciplinary. Information and Communication. Health.

\footnotetext{
${ }^{1}$ Jornalista (UFJF), Especialista em Marketing (UFJF), Mestre em Comunicação e Informação em Saúde (Fiocruz).
} 


\section{Introdução}

O cenário atual vem se configurando a partir de novos modelos e paradigmas. A sociedade do século XXI é vivaz e complexa. Por isso, cada vez mais as dinâmicas sociais são repensadas e reestruturadas. Uma questão em voga que parece se inserir nesse contexto é a interdisciplinaridade. De fato, o interdisciplinar tem mostrado que não é apenas um modismo, mas uma possibilidade eficaz para resolver problemáticas contemporâneas.

Ainda que a perspectiva interdisciplinar não seja tão recente, fica visível que ela tem se colocado, a princípio, mais como desafio do que como resposta para todos os problemas de natureza complexa e diversa. Enquanto elemento integrador de diferentes campos, a interdisciplinaridade demonstra que é possível pensar além do disciplinar e propor novos olhares e pontos de vista. Nesse sentido, assiste-se à configuração de um novo campo, o da "Informação, Comunicação e Saúde".

Saúde, Comunicação e Informação são campos que operam de modo disciplinar e cada qual tem a sua própria constituição e configuração. Por essa razão, promover o diálogo e a interação entre esses domínios não é tarefa fácil. Exatamente por isso pretende-se trabalhar com a ideia de contexto, uma vez que a visão contextual possibilita uma compreensão mais prática do que se refere à noção de campo.

A palavra contexto pode ser entendida como o "conjunto de circunstâncias físicas, sociais, psicológicas que envolvem e determinam o ato de enunciação. Só com o conhecimento do contexto, torna-se possível a interpretação correta dessa enunciação” (RABAÇA, 2001, p. 183). Assim, a definição exposta impõe uma condição de experiência cognitiva, pois "estes contextos são campos de luta simbólica e, como tal, espaços onde os agentes desenvolvem estratégias de manutenção ou transformação da ordem dominante, seja econômica, política, ou discursiva” (ARAÚJO, 2009, p. 45). Ao refletir o olhar subjetivo, o termo 'contexto' acaba por demonstrar toda a complexidade inerente ao processo de produção de sentidos.

Partindo do princípio de que o termo contexto, ao refletir o olhar subjetivo, acaba por demonstrar toda a complexidade inerente ao processo de produção de sentidos, o presente estudo pretende investigar o desenvolvimento desse campo, a partir de uma revisão de literatura. Para tanto, o trabalho está dividido em três partes. Na primeira, será realizado um estudo sobre o Contexto da Saúde em busca de entender sua trajetória histórica, epistemológica, social e científica. Num segundo momento, haverá uma reflexão sobre os campos da Saúde e das Ciências Sociais, 
expondo o Contexto Interdisciplinar. Já a terceira parte tem como propósito apontar as diretrizes do campo em formação, as quais se inserem no Contexto das Mediações.

\section{O Contexto da Saúde: o objeto "Saúde" e sua construção epistêmica, histórica, social e científica}

Segundo a definição da Organização Mundial de Saúde (OMS), "saúde é o estado do mais completo bem-estar físico, mental e social e não apenas a ausência de enfermidade" (1948). Embora seja alvo de críticas e debates polêmicos, os quais não serão tratados neste trabalho, esse conceito é usado até os dias atuais e representa a visão transnacional em vigor da Saúde. Sabemos que a ampla dimensão da episteme, do conceito, do campo e do objeto da Saúde lhe confere um aspecto complexo e dinâmico.

\subsection{Epistemologia da saúde: os conceitos de normal e patológico}

Traçar uma epistemologia da saúde implica recorrer à história em busca de entender o significado dessa palavra. Desde o início das civilizações, existe a dificuldade de se compreender o termo "Saúde”. Segundo Georges Canguilhem (1990, p. 19), “a medicina egípcia provavelmente generalizou a experiência oriental das afecções parasitárias, combinando-a com a idéia da doençapossessão". Como não poderia ser diferente, cada sociedade, de acordo com o seu contexto em determinado tempo e espaço, assinala sua contribuição para a construção do objeto Saúde. A civilização grega, por exemplo, conforme diz Canguilhem, oferece uma percepção totalizante da enfermidade.

Na obra O Normal e o Patológico (1990) Canguilhem apresenta duas concepções de doença presas à noção de que o estado patológico nada mais é do que uma modificação quantitativa do estado normal. Enquanto a primeira relaciona a enfermidade a um agente externo estranho ao corpo, a outra trata o agente da enfermidade como interno ao corpo, o qual viria para perturbar-lhe o equilíbrio dos humores. A oposição entre essas correntes incorpora-se na discussão entre Auguste Comte e Claude Bernard. O primeiro pensador parte do patológico para estudar o normal enquanto o segundo, do normal para explicar o patológico. Ambas as visões apontam para um entendimento positivista da Saúde. "Esta é a ideia positivista fundamental: saber para agir. A fisiologia deve explicar a patologia para estabelecer as bases da terapêutica” (CANGUILHEM, 1990, p. 74). 
A partir desses pontos de vista, o autor traz à reflexão o estudo da arte clínica praticada por um técnico, René Leriche, que, assim como Claude Bernard, "afirma também uma continuidade e a indiscernibilidade do estado fisiológico e do estado patológico" (CANGUILHEM, 1990, p.70). Nesse âmbito, a fisiologia não basta para explicar a doença, visto que é a própria doença que revela a fisiologia. O autor de $O$ Normal e o Patológico faz duas importantes críticas a essas concepções. A primeira está relacionada à dificuldade de separar a opinião científica da crença religiosa e a segunda refere-se à redução da qualidade em virtude da quantidade. Com base nesse panorama, Canguilhem questiona se a saúde é uma ciência da doença ou da vida. Nesse sentido, as noções de normal e patológico aparecem articuladas, sob uma mesma lei ou racionalidade. Ao afirmar que "o estado patológico ou anormal não é consequência da ausência de qualquer norma" (CANGUILHEM, 1990, p.146), Canguilhem rompe com a ideia de saúde como adequação à norma: "a saúde perfeita não passa de um conceito normativo, ideal. Raciocinando com todo o rigor, uma norma não existe, apenas desempenha seu papel que é de desvalorizar a existência para permitir a correção dessa mesma existência" (CANGUILHEM, 1990, p. 54).

\section{$1.2 O$ nascimento da clínica médica}

Assim como as concepções de saúde foram (e certamente vão) se modificando, a sociedade também vai estabelecendo suas instituições e instâncias de poder. Na área da saúde, Foucault (2006) estudou o nascimento da medicina social e do hospital.

Foucault substituía a concepção canguilhemiana de uma norma produzida pela vida por uma noção de norma construída pela ordem social e portadora de normalização. Ou seja, opunha uma normatividade social à normatividade biológica, uma arqueologia à fenomenologia. (ROUDINESCO, 2007, p. 45).

A abordagem foucaultiana reside, então, na expressão do poder. "O poder é alguma coisa que opera através do discurso, já que o próprio discurso é um elemento em um dispositivo estratégico de relações de poder" (FOUCAULT, 2006, p. 253).

Segundo Foucault (2006), a origem da clínica médica data do fim do século XVIII. Para ele, o capitalismo propiciou a passagem de uma medicina privada a uma medicina coletiva e não o contrário, à medida que "socializou um primeiro objeto que foi o corpo enquanto força de produção, força de trabalho. O controle da sociedade sobre os indivíduos não se opera simplesmente pela consciência ou ideologia, mas começa no corpo, com o corpo" (FOUCAULT, 2006, p.80). É sob 
esse prisma que se encarna o significado de biopoder, o qual surge em "uma sociedade em que o poder político acabava de assumir a tarefa de gerir a vida" (FOUCAULT, 1999, p. 131).

O filósofo aponta três etapas na formação da medicina social européia: a) a medicina de Estado (Alemanha - século XVIII), em que Foucault afirma que, com o mercantilismo, todas as nações do mundo europeu se preocuparam com o estado de saúde de sua população em um clima político, econômico e científico; b) a medicina urbana (França - século XVIII), quando o problema da unificação do poder urbano traz à tona a necessidade de constituir a cidade como unidade, de organizá-la de modo coerente, homogêneo, dependendo de um poder único e bem regulamentado. c) a medicina dos pobres (Inglaterra - século XIX), em que Foucault enfatiza que somente no século XIX o pobre apareceu como perigo, em razão das revoltas que emergiram durante a Revolução Francesa e agitações sociais na Inglaterra, da implantação de novos sistemas que dispensavam os serviços da mão de obra, assim como da cólera de 1832, a qual cristalizou em torno da população proletária uma série de medos políticos e sanitários. Sendo assim, criou-se a Lei dos pobres que, ao mesmo tempo em que representava uma assistência controlada, também significava proteção para as classes mais altas.

Com base nesses três momentos, o autor francês mostra como se deu o processo de formação da medicina social, expondo suas origens e contextos.

Enquanto o sistema alemão da medicina de Estado era pouco flexível e a medicina urbana francesa era um projeto geral de controle sem instrumento preciso de poder, o sistema inglês possibilitava a organização de uma medicina com faces e formas de poder diferentes segundo se tratasse da medicina assistencial, administrativa e privada, setores bem delimitados que permitiram, durante o final do século XIX e primeira metade do século XX, a existência de um esquadrinhamento médico bastante completo. (FOUCAULT, 2006, p. 97-98).

O desenvolvimento do hospital também data desse período, quando foi realizada uma série de inquéritos empíricos, os quais faziam visita comparada às casas de saúde. O inquérito se constituía, assim, num "conhecimento que se tornou científico quando a medicina se transformou em uma ciência empírica" (MACHADO, 1981, p. 97). A reforma hospitalar ocorreu justamente no século XVIII. Segundo Foucault, os hospitais da Europa, os quais funcionavam desde a Idade Média, não eram instituições médicas de fato, ou seja, não eram concebidos para curar. "A medicina é, nesta época, uma prática não hospitalar" (FOUCAULT, 1979, p.101). O principal fator para a transformação hospitalar seria a necessidade de anular os efeitos negativos provocados pelo 
ambiente do hospital. Este não só trazia como perigo a propagação eminente de doenças à população das cidades, como também desordens econômicas e sociais. Um dos principais mecanismos que propiciou essa reordenação foi uma tecnologia política - a disciplina - técnica de exercício do poder capaz de exercer o controle e vigilância sobre os indivíduos. Portanto, “a formação de uma medicina hospitalar deve-se, por um lado, à disciplinarização do espaço hospitalar e, por outro, à transformação, nesta época, do saber e da prática médica" (FOUCAULT, 1979, p. 106).

\subsection{A polícia médica e a institucionalização da Saúde}

A noção de disciplinarização de Foucault estabelece relação direta com o sentido de polícia médica de George Rosen (1987). Implantado no século XVIII, o conceito marca uma nova fase de desenvolvimento de interesse por política pública. Dentre os pontos do programa de polícia médica, destacam-se: o registro dos fenômenos epidêmicos ou endêmicos, através da observação da morbidade; a normalização do ensino através de um controle pelo Estado dos programas de ensino; e a criação de um corpo de funcionários médicos competentes, nomeados pelo governo, para interferir sobre uma determinada região. Nesse cenário, nasce a figura do médico como administrador da saúde, ou seja, o profissional que se preocupava em "manter o crescimento da população, garantir um número suficiente de médicos ou de pessoal médico competente e decretar as leis necessárias para a manutenção e promoção da saúde pública” (ROSEN, 1987, p. 177).

Pode-se considerar que a prática da polícia médica iniciou-se nos primórdios da institucionalização da saúde, sendo os primeiros passos para a consolidação de um setor socialmente instituído.

\section{O Contexto Interdisciplinar: o campo da saúde e sua constituição histórica, científica e} social - interdisciplinaridade entre Saúde e Ciências Sociais

A partir do percurso histórico e epistemológico da Saúde, fica mais fácil entender sua relação com as Ciências Sociais. A confluência entre esses dois campos aparece, assim, sob uma perspectiva interdisciplinar, como "tentativa de romper o caráter estanque das disciplinas", como ressalta Olga Pombo (2004, p.5).

A interdisciplinaridade coloca-se como desestímulo à multiplicação desordenada de especialidades, buscando as relações de interdependências e de conexões recíprocas entre as disciplinas; caracteriza-se pela intensidade das trocas entre 
especialistas e pelo grau de integração real das disciplinas, no interior de um mesmo projeto de pesquisa. (GATTÁS; FUREGATO, 2006, p. 324).

Nesse contexto, um conceito importante é a "fragilização das fronteiras" (POMBO, 2004), o qual pressupõe que as fronteiras do conhecimento científico precisam ser reformuladas. A pesquisadora Maria Nélida Gonzalez de Gómez (2005) destaca dois marcos importantes do desenvolvimento dos estudos sobre a interdisciplinaridade. O primeiro data da década de 70 do século XX, quando "uma crise pela que passaria a instituição universitária e suas formas de organizar e coordenar os conhecimentos" (GÓMEZ, 2005, p. 24) faz emergir os discursos sobre a interdisciplinaridade. O outro marco acontece na década de 1990, momento em que se passou a "pensar a transdisciplinaridade, associando novas demandas éticas e políticas à busca de inovações epistemológicas" (GÓMEZ, 2005, p. 25).

\subsection{Saúde e Ciências Sociais: o que há em comum?}

A partir da abordagem interdisciplinar, procura-se entender o que há em comum entre a Saúde e as Ciências Sociais. À medida que a Saúde foi ampliando seus horizontes e fronteiras, a presença das Ciências Sociais e Humanas foi se consolidando nessa área, sendo, inclusive, “considerada fundamental para a compreensão dos processos da vida, do adoecimento, da morte e das relações entre médicos e pacientes" (NUNES, 2006, p. 314).

Ao investigar a saúde e a doença como expressões culturais, Maria Cecília Minayo (1997) apresenta uma discussão sobre a representação social da saúde e da doença, refletindo a partir do ponto de vista social. Para ela, essa representação seria constituída pelas vivências do homem.

Do ponto de vista mais geral, a representação social não é meramente uma opinião, a opinião a integra. A maneira como se constrói um hospital ou um centro de saúde, de certa forma, cristaliza uma representação social própria de saúde e doença. Num hospital em que a enfermaria de pediatria só possui espaço para a criança sozinha, desacompanhada da mãe, está se expressando um tipo de concepção de saúde e doença que pode ser resolvida apenas por intervenções médicas. Ou seja, na concepção dominante, saúde e doença são algo organicamente localizado, a ser tratado por meio de um medicamento, de uma cirurgia. Esse é o modelo biomédico dominante em nossa sociedade. (MINAYO, 1997, p. 32).

Ao dizer que "a cor é uma realidade construída", o antropólogo Lévi-Strauss (1976) também chama a atenção para a representação social. Nessa direção, "saúde e doença, portanto, não são apenas efeitos biológicos, mas também acontecimentos culturais historicamente construídos de 
diferentes formas em diferentes sociedades" (MINAYO, 1997, p. 33). É essa noção da heterogeneidade cultural que parece fundamentar a imagem de realidade construída, mesmo porque "a diversidade das culturas humanas não deve induzir a uma observação fragmentária ou fragmentada. Ela é menos função do isolamento dos grupos que das relações que os unem" (LÉVISTRAUSS, 1976, p. 57). Seguindo essa linha de raciocínio, é possível perceber o alerta que é feito sobre a visão etnocêntrica pela qual a sociedade ocidental está acostumada a se guiar.

\begin{abstract}
Na nossa sociedade capitalista, desigual, injusta e iníqua, para pensar saúde e doença, têm-se que assumir as contradições geradas pelas desigualdades econômicas, políticas, sociais e ideológicas, que se expressam nas concepções e práticas de saúde e doença. Nessa sociedade contraditória, saúde e doença são pensadas, em primeira instância, como fatores de produção, e o sistema de saúde é organizado de forma a tornar o indivíduo produtivo. (MINAYO, 1997, p. 34).
\end{abstract}

Para Minayo (1997, p. 34), “a concepção biomédica reduz a doença e a saúde ao contorno biológico individual, separando o sujeito de seu contexto integral de vida”. Portanto, a seu ver, o grande desafio da saúde coletiva está nessa "concepção mais abrangente que integra as políticas sociais, as condições de vida e também a sensibilidade para a riqueza e a diversidade cultural" (MINAYO, 1997, p. 39).

\title{
2.2 XVIII Conferência Nacional de Saúde: marco da criação do SUS
}

No Brasil, a história do sistema de saúde brasileiro pode ser dividida em três grandes momentos: o sanitarismo campanhista (início do século XX até metade dos anos 1960); o modelo médico-assistencial privatista (anos 1960 a 1980); e o sistema público vigente segmentado e plural que inclui o SUS.

Em 1986 foi realizada a VIII Conferência Nacional de Saúde Pública, a qual contava com representações diversas da sociedade civil. A importância da conferência reside no fato de que o seu relatório final foi instrumento fundamental para a nova Constituinte Federal: "Saúde é um Direito de Todos e um Dever do Estado" (BRASIL, 1988). Foi nesse momento que a saúde foi incluída nos direitos sociais da cidadania. Além disso, a proposta de Reforma Sanitária consolidou-se no desenvolvimento do Sistema Único de Saúde (SUS), que tem como principais princípios: a universalidade do acesso, a integralidade da assistência, a igualdade da assistência, a participação da comunidade, a descentralização político-administrativa, a regionalização, a hierarquização e a 
capacidade de resolução dos serviços em todos os níveis de atenção. "O projeto do SUS é uma política de construção da democracia que visa à ampliação da esfera pública, a inclusão social e a redução das desigualdades" (FORUM, 2006, p. 2). Ainda que a Reforma Sanitária brasileira necessite de aprimorar mecanismos para assegurar seus princípios fundamentais, ela representa um passo importante para o setor de Saúde no país e diversos eixos da sociedade participam desse processo e apresentam iniciativas de movimentação político-social.

\section{O Contexto das Mediações: Informação, Comunicação e Saúde - marcos históricos e epistemológicos, objetos, práticas e questões}

Com base na abordagem que aproxima Ciências Sociais e Saúde, pode-se compreender a formação de um campo interdisciplinar que integra três áreas distintas do conhecimento científico. Por sua diversidade e complexidade, o campo da "Informação, Comunicação e Saúde" não deve ser explicado apenas sob a ótica interdisciplinar, uma vez que lida com problemáticas e embates tanto no contexto prático, como no teórico. Sendo assim, o termo mediação parece fazer mais sentido, uma vez que esta "pode ser definida, sem dúvida, a nível funcional: visa fazer aceder um público a obras (ou saberes) e a sua ação consiste em construir um interface entre esses dois universos estranhos um ao outro (o do público e o, digamos, do objeto cultural) com o fim precisamente de permitir uma apropriação do segundo pelo primeiro" (DAVALLON, 2003, p. 4).

Ao levantar o aspecto da interface, tal definição vem ao encontro da perspectiva de Pombo (2004), quando fala da "fragilização das fronteiras" que, por sua vez, expressa o domínio de “campos de luta simbólica” (ARAÚJO, 2009). Dessa forma, a noção de mediações parece integrar todas as confluências de um campo interdisciplinar em formação. A mediação, portanto, também pode ser compreendida como uma “construção teórica destinada a refletir sobre as práticas e os dispositivos que compõem os arranjos de sentidos e formas comunicacionais e informacionais nas sociedades atuais, sem perder de vista os elos que, tanto os conteúdos quanto os suportes e os acervos, mantêm com a tradição cultural” (MARTELETO, 2009, p. 19). O sentido da prática cultural que emerge desse conceito pode ajudar a entender os passos e desafios da construção do campo Informação, Comunicação e Saúde.

\subsection{A formação do campo}


Por unir três pontas do conhecimento, o campo da Informação e Comunicação e Saúde acaba sendo subdivido em outros três: Informação e Saúde; Comunicação e Saúde; e Informação e Comunicação.

Figura 1 - Formação do campo

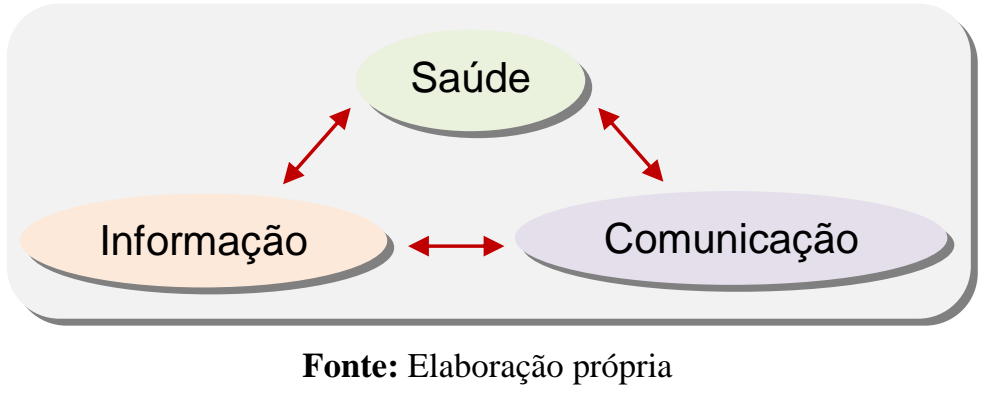

\subsubsection{Informação e Saúde}

Desde o século XVIII, quando surge o médico como administrador de saúde, já é possível perceber uma abordagem interdisciplinar entre a Informação e a Saúde. Afinal, existia a tentativa de quantificar os fenômenos dentro do hospital, convertendo-os em dados. "Como parte constitutiva desse momento histórico (final do século XVIII e início do século XIX), o Estado Moderno estabelece dispositivos de atuação voltados para a gestão da vida, que permitem o exercício de um poder disciplinar que se expressa capilarmente em todo o campo social, de um biopoder" (HAMERLI; GÓMEZ, 2007, p. 555). Hoje, com o desenvolvimento tecnológico, esse aparato é ainda mais desenvolvido e ampliado. “'Informação em Saúde’ designa, assim, o enquadramento dos significados da saúde reconstruídos e alargados na nova ordem da medicalização e das instituições primeiro de atendimento e depois de ciência e tecnologia em saúde" (HAMERLI; GÓMEZ, 2007, p. 558).

Não só as tecnologias são importantes para a Informação e Saúde, como também a análise estatística, a qual propiciou o processamento e análise de dados, antes mesmo do desenvolvimento da informática. "É possível que as atuais práticas e saberes da área temática IIS [informação e informática em saúde] não deem conta da complexidade dos processos saúde-doença-cuidado, mas essas ilustrações indicam muito do que pôde ser feito antes mesmo da existência de sistemas de informação e, particularmente, da informática” (PAIM, 2007, p. 566). 


\subsubsection{Comunicação e Saúde}

Outra relação que se integra ao campo da Informação, Comunicação e Saúde é a Comunicação e Saúde, a qual "é constituído pelos elementos de cada campo separadamente - da comunicação e da saúde -, porém na sua interface" (ARAÚJO; CARDOSO, 2007, p. 20). Diversas questões desse contexto vêm sendo tratadas em vários níveis de âmbito institucional, conforme apontam Araújo e Cardoso (2007), como em grupos de trabalho, cursos de pós-graduação, oficinas e cursos de curta duração e Conferências Nacionais de Saúde. Fausto Neto (2007) alerta para a questão de que os esforços e iniciativas para dar sequência a estes processos se constituem numa tarefa muito desafiadora, "uma vez que o diálogo entre os campos - seja por seus pesquisadores e suas instituições científicas - se trava de modo lento" (NETO, 2007, p. 202).

A relação entre esses dois domínios do conhecimento impõe a necessidade de estabelecer agendas inclusivas. "A comunicação em saúde se constitui no esforço em pensar e propor encaminhamentos e reflexões inovadores, marcados pela presença da doença, capital e tecnologia. A comunicação exige o enfrentamento de linguagens verbais e não verbais de produção de sentido [...]. Trata-se de elemento estratégico para a gestão social da saúde e qualidade de vida" (MORAES, 2007, p. 65). Além disso, "a emergência da midiatização como uma ambiência, e a força dos seus processos, torna a questão da saúde um tema intensamente presente na esfera pública” (NETO, 2007, p. 202).

\subsubsection{Informação e Comunicação}

Essa relação parece confluir num sentimento misto de amor e ódio, uma vez que, sendo campos afins, há a dificuldade de diferenciá-los, o que pode acarretar, ao mesmo tempo, pontos positivos e negativos.

A Teoria da Informação é também conhecida por Teoria da Comunicação e Teoria da Informação e da Comunicação. Alguns teóricos e estudiosos chegam mesmo a distinguir entre informação e comunicação, o que nos parece um eco de uma outra distinção bastante arraigada e corrente, mas dificilmente sustentável, que seja, a distinção entre forma e fundo, entre forma e conteúdo. (PIGNATARI, 1973, p. 11).

Ao falar das "sociedades de saberes", Mattelart (2005) aponta para a indissociabilidade entre a comunicação e o conhecimento ou informação. "Cultura, conhecimento, mídia. Todos esses campos têm algo em comum. Uma verdadeira política cultural indissociável a uma política de 
comunicação, ela própria indissociável de uma política de ensino e de pesquisa científica. E reciprocamente" (MATTELART, 2005, p. 20).

\subsection{Desafios do campo Informação, Comunicação e Saúde}

Como demonstrado ao longo deste trabalho, são inúmeros os desafios e provações do campo Informação, Comunicação e Saúde. Um deles está no fato de que as Ciências da Informação e da Comunicação sofrem, normalmente, de um reducionismo técnico e são alvo de preconceito do campo da Saúde. “A 'informação em saúde' é, politicamente, reduzida a um campo de império de tecnicidade: é apresentada como 'despolitizada', como 'neutra"' (HAMERLI; GÓMEZ, 2007, p. 555). Portanto, caso essa concepção não seja mudada, pode acarretar sérios prejuízos para o campo.

\footnotetext{
Observa-se que a informação em saúde surge de um certo "pré-juízo" de sinais, sintomas, signos e práticas relacionados ao processo de saúde/doença/cuidado que, em um determinado contexto histórico, adquirem relevância política e social: tornam-se eventos que justificam seu monitoramento, sua visibilidade, sua vigilância através de dispositivos de Estado no exercício de um biopoder. (HAMERLI; GÓMEZ, 2007, p. 554).
}

Jean Davallon (2009) também alerta para a questão e afirma que a consequência prática imediata ao fato de as duas ciências aparecerem na sociedade sob a forma de meios e de processos é que "o lugar dado pela sociedade às ciências da informação e da comunicação é espontaneamente o de uma teoria do objeto técnico - quer dizer, em sentido estrito, de uma tecnologia" (DAVALLON, 2009 , p. 36). Uma possível justificativa para esse modo de ver pode estar no dilema vivido pelas disciplinas da Informação e da Comunicação, ou seja, o desafio de "conciliar estudos sobre o fenômeno da informação em nosso tempo com estudos das práticas sociais e públicas, das realidades políticas, da economia e da cultura" (FHROMANN, 2008, p. 19).

Outro desafio para o campo está centrado na fragmentação do saber, a ponto de os estudiosos Gómez (2005) e Moraes (2007) falarem de um "sucateamento e fragmentação dos espaços de gestão pública da informação e informática em saúde, acarretando um processo conhecido como lock in (dependência/aprisionamento a empresas, plataformas e/ou sistemas)" (HAMERLI; GÓMEZ, 2007, p. 555). Esses dois processos, o do reducionismo técnico e o da fragmentação, podem ocasionar entraves para a consolidação da nova plataforma de conhecimento científico. 


\section{Considerações Finais}

Dilemas, embates e contradições parecem se mesclar a perspectivas, horizontes e desafios quando se trata do processo de desenvolvimento de uma nova arena do conhecimento a qual integra três diferentes e consolidadas áreas - Informação, Comunicação e Saúde - tendo uma delas - a Saúde - como destaque. Nessa nova proposta de domínio científico, a Saúde aparece como uma ciência mais consolidada, tanto por sua perspectiva histórica quanto por sua dimensão cultural. Por outro lado, a Informação e a Comunicação, além de serem campos mais recentes, sofrem de preconceito, conforme abordado no último item. Por essa razão, acredita-se que o processo de formação desse campo é lento e demorado em virtude dos inúmeros obstáculos que deve superar.

O presente trabalho configura-se na reflexão acerca da formação desse novo campo do conhecimento, preocupando-se prioritariamente com o contexto das áreas envolvidas. No entanto, este estudo não avança na materialidade da questão de maneira que uma pesquisa voltada para as constituições práticas desse campo poderia apontar constatações mais fidedignas à realidade desse processo.

Sabe-se que a construção do conhecimento é dinâmica e necessita de interação. Por isso, o campo deve ser socialmente construído. Dessa maneira, ao se pensar em Informação, Comunicação e Saúde, a imagem que poderia representar essa condição seria a de um mosaico em formação, uma vez que o mosaico refletiria a atitude de promover conexões entre as ciências. Olhando de perto, poderiam ser vistos apenas fragmentos de origens diversas, mas ao se distanciar do objeto seria possível ver uma realidade coesa, consistente e harmoniosa. É por esse motivo que os esforços devem valer a pena, ainda que não seja possível mensurar quando (nem se) o mosaico será um dia finalizado.

\section{Referências}

ARAÚJO, Inesita. Contextos, mediações e produção de sentidos: uma abordagem conceitual e metodológica em comunicação e saúde. RECIIS, v.3, n.3, p. 42-49, 2009.

BRASIL. Constituição (1988). Constituição da República Federativa do Brasil. Brasília, DF: Senado, 1988.

2007. .; CARDOSO, Janine Miranda. Comunicação e Saúde. Rio de Janeiro: Editora Fiocruz, CANGUILHEM, Georges. O normal e o patológico. 3. ed. Rio de Janeiro: Forense Universitária, 1990.

DAVALLON, Jean. A mediação: a comunicação em processo? PRISMA.com: Revista de Ciências da Informação e Comunicação, [S.1], 2003. Disponível em: 
<http://prisma.cetac.up.pt/A_mediacao_a_comunicacao_em_processo.pdf >. Acesso em: 20 jun. 2010.

. Objecto concreto, objecto científico, objecto de investigação. PRISMA.com: Revista de Ciências da Informação e Comunicação, n. 9, p. 33-48, dez. 2009.

FOUCAULT, Michael. Diálogo sobre o poder. In: MOTTA, M. B. da (Org.). Estratégia, podersaber. 2 ed. Rio de Janeiro: Forense Universitária, 2006. p. 253-266.

. História da Sexualidade. 13 ed. Rio de Janeiro: Edições Graal, 1999.

. Microfísica do Poder. Rio de Janeiro: Edições Graal, 1979.

FORUM da Reforma Sanitária Brasileira. O SUS prá valer: universal, humanizado e de qualidade.

Abrasco, Cebes, Abres, Rede Unida e Ampasa. 2006. Disponível em:

<http://www.abrasco.org.br/publicacoes/arquivos/20070306142552.pdf >. Acesso em: 03 jul. 2010. FROHMANN, Bernd. O caráter social, material e público da informação. In: FUJITA, Mariângela S. L.; MARTELETO, Regina Ma.; LARA, Marilda L. G. de. A dimensão epistemológica da Ciência da Informação e suas interfaces técnicas, políticas e institucionais nos processos de produção, acesso e disseminação da informação. São Paulo: Ed. Cultura Acadêmica; Marília: Ed. Fundepe, 2008. p.19-34.

GATTÁS, Maria Lúcia Borges; FUREGATO, Antonia Regina Ferreira. Interdisciplinaridade: uma contextualização. Acta Paulista de Enfermagem, v. 19, n. 3, p. 323-327, jul./set. 2006.

GÓMEZ, Maria Nélida Gonzalez de. A vinculação dos conhecimentos: entre a razão mediada e a razão leve. Liinc em Revista, v. 01, n. 01, p. 16-37, mar. 2005.

HAMERLI, Ilara S.; GÓMEZ, Ma. Nélida Gonzalez de. Informação e informática em saúde: caleidoscópio contemporâneo da saúde. Ciência \& Saúde Coletiva, v. 12, n.3, p. 553-565, mai./jun. 2007.

LÉVI-STRAUSS, Claude. Raça e História. In: Os pensadores. São Paulo: Ed. Abril, 1976. p. 5194.

MACHADO, Roberto. Ciência e saber: a trajetória da arqueologia de Foucault. São Paulo: Ed. Graal, 1981.

MINAYO, Maria Cecília de Souza. Saúde e doença como expressão cultural. In: AMÂNCIO FILHO, Antenor; MOREIRA, Maria Cecilia G. B. Saúde, trabalho e formação profissional. Rio de Janeiro: FIOCRUZ, 1997. p.31-39.

MORAES, Nilson A. Comunicação e saúde: entre sentidos, interesses e estratégias. ECO-PÓS publicação da pós-graduação em comunicação e cultura, v. 10, n. 01, p. 64-78, jan./jun. 2007. NETO, Antônio Fausto. Entrevista comunicação e saúde. ECO-PÓS - publicação da pósgraduação em comunicação e cultura, v. 10, n. 01, p. 198-206, jan./jun. 2007.

NUNES, Everardo Duarte. Saúde Coletiva: uma história recente de um passado remoto. In: CAMPOS, Gastão Wagner de Sousa et al. Tratado de saúde coletiva. Rio de Janeiro, Hucitec: Fiocruz, 2006. p. 295-315.

PAIM, Jairnilson Silva. Informação e política de saúde. Ciência \& Saúde Coletiva, v. 12, n.3, p.566-567, mai./ jun. 2007.

PIGNATARI, Décio. Informação. Linguagem. Comunicação. São Paulo: Ed. Perspectiva, 1973. POMBO, Olga. Epistemologia da interdisciplinaridade. In: PIMENTA, Carlos (Coord.).

Interdisciplinaridade, humanismo, universidade. Porto: Campo das Letras, 2004. Disponível em: $<$ http://www.educ.fc.ul.pt/docentes/opombo/investigacao/pontofinal.pdf $>$. Acesso em: 12 nov. 2004.

Interdisciplinaridade e integração dos saberes. Liinc em Revista, v. 1, n. 1, p. 3-15. 2005. 
RABAÇA, Carlos Alberto; BARBOSA, Gustavo Guimarães. Dicionário de comunicação. 8. ed. Rio de Janeiro: Elsevier, 2001.

ROSEN, George. A polícia médica. Rio de Janeiro: Graal, 1987.

ROUDINESCO, Elisabeth. Filósofos na tormenta. Rio de Janeiro: Zahar, 2007. 